\title{
A TRAJETÓRIA PROFISSIONAL DE FLORA COSTA MARQUES: EX-ALUNA DA ESCOLA DE ENFERMAGEM AURORA DE AFONSO COSTA (1950-1983)
}

The professional trajectory of Flora Costa Marques: former student of the Aurora de Afonso Costa School of Nursing (1950-1983)

La trayectoria profesional de Flora Costa Marques:

ex-alumna de la Escuela de Enfermería Aurora de Afonso Costa (1950-1983)

\section{Resumo}

A pesquisa de cunho histórico social descreve a trajetória de Flora Costa Marques, uma ex-aluna da antiga Escola de Enfermagem do Estado do Rio de Janeiro, atual Escola de Enfermagem Aurora de Afonso Costa, na Saúde Pública do município de Niterói, destacando as contribuições da Escola à formação de enfermeiras para atuação no campo da saúde pública. 0 recorte temporal é de 1950, ano de formatura da segunda turma do curso de graduação em enfermagem da referida escola, a 1983, ano da aposentadoria da enfermeira. Utilizamos o método história de vida e como técnica de coleta a entrevista aberta. Ao analisarmos a trajetória da enfermeira, observamos que as atividades desenvolvidas na época remetem aos Programas atuais: Programa Saúde da Família, Programa Médico da Família e Programa Agentes Comunitários de Saúde. Assim, as contribuições da Escola, com ênfase na área da saúde pública, consolidaram-se através do preparo de enfermeiras que lidam com as mais variadas adversidades no campo da saúde.

Palavras-chave: História da Enfermagem. Pesquisa. Biografia. Saúde pública.

\section{Abstract}

The research with social and historical approach describes the trajectory of Flora Costa Marques, a former student of the former Nursing School of Rio de Janeiro State, nowadays Nursing School Aurora de Afonso Costa, in the public health in the city of Niterói, outstanding the School contributions to the graduation of nurses for working in the public health field. The time is from 1950, year of graduation of the second class in nursing of the mentioned school, through 1983, year in which the nurse retired. We used the life story method and as data collecting technique the open interview. When we analyzed the trajectory of the nurse, we observed that the activities developed at the time remit to Programs nowadays existing: PSF, PMF, PACS. So, the School contributions, with emphasis in the public health area, have been consolidated through the preparing of nurses who face the most varied diversities in the field of health.

Keywords:

Nursing History. Research. Biography. Public Health.

\section{Resumen}

a investigación de enfoque histórico y social describe la rayectoria de Flora Costa Marques, una ex-alumna de la antigua Escuela de Enfermería del Estado de Rio de Janeiro - Brasil, actual Escuela de Enfermería Aurora de Afonso Costa, en la Salud Pública del municipio de Niteroi, destacando las contribuciones de la Escuela a la formación de enfermeras para actuación en el campo de la salud pública. El tiempo va desde 1950, año de la licenciatura de la segunda turma del curso de graduación de enfermeros de la referida scuela, hasta 1983, año de la jubilación de la enfermera. Utilizamos el método historia de vida y como técnica de colecta la entrevista abierta. Al analizar la trayectoria de la enfermera, se ha observado que las actividades a la época remiten a los Programas actuales: Programa Salud de la Familia, Programa Médico de Familia y Programa Agentes Comunitarios de Salud. Así, las contribuciones de la Escuela con énfasis en el área de la salud pública, se han consolidado a través del preparo de enfermeras que trabajan con las más variadas adversidades en el campo de la salud.

Palabras clave:

Historia de la Enfermería. Investigación. Biografía. Salud Pública. 


\section{INTRODUCẼ̃O}

A iniciativa deste estudo surgiu a partir do momento em que uma das autoras buscava dados para a elaboração de um trabalho científico, e acabou se deparando com um momento ímpar de resgate da história da Escola de Enfermagem Aurora de Afonso Costa e suas contribuições para a saúde pública do município de Niterói: a história de Flora Costa Marques, uma enfermeira aposentada, formada na segunda turma dessa Escola, ${ }^{a}$ em 1950, na época denominada Escola de Enfermagem do Estado do Rio de Janeirob.

Assim, considerando que ainda são poucos e raros os registros, em pesquisas históricas, abordando a Escola de Enfermagem Aurora de Afonso Costa, o cotidiano das alunas e a inserção das mesmas na vida profissional, em rede hospitalar ou em saúde pública, resolvemos documentar um pouco dessa historia a partir do depoimento de Flora, pois, preservar a memória é ao mesmo tempo, responsabilidade social do docente de enfermagem e da unidade de ensino à qual pertence, para que se possa legar, aos que nos sobrevirão, conhecimento crítico sobre as nossas origens e a nossa trajetória como profissão (Nogueira: ${ }^{130}$ ).

A história narrada por Flora nos proporcionou uma viagem ao passado e também nos instigou a refletir em como as sementes por ela lançadas hoje revestem os programas governamentais, tipo Programa Saúde da Família, Programa Médico de Família, Programa de Agentes Comunitários de Saúde, entre outros.

Entretanto, para Santos et al. ${ }^{2}$, é de se estimar que os enfermeiros formados pela Escola de Enfermagem do Estado do Rio de Janeiro conquistaram seus espaços com muita dedicação e construíram suas histórias com brilhantismo.

A presente pesquisa, de cunho histórico, social e descritivo, teve como objetivo descrever a trajetória profissional de uma ex-aluna da Escola de Enfermagem do Estado do Rio de Janeiro, atual Escola de Enfermagem Aurora de Afonso Costa, na Saúde Pública em Niterói, destacando as contribuições da Escola no que se refere à formação de enfermeiras para atuação no campo da saúde pública.

Fomos orientadas pelo seguinte questionamento: Qual a contribuição da Escola de Enfermagem, através de uma ex-aluna, para a saúde pública de Niterói?

0 recorte temporal é de 1950, ano de formatura da segunda turma do Curso de Graduação em Enfermagem da Escola de Enfermagem do Estado do Rio de Janeiro, e início da trajetória profissional da enfermeira, até 1983, quando a mesma se aposentou.

\section{O CAMINHO TEÓRICO-METODOLÓGICO}

A história de vida foi o método utilizado para esta pesquisa e a técnica para a coleta dos dados foi a entrevista aberta, sem perguntas predeterminadas ou padronizadas, possibilitando, assim, centrar na ex-aluna o foco da investigação.

Ouvir a história de vida de Flora, mesmo sujeita a determinismos sociais específicos, mostrou-nos ser um processo extremamente rico pela profundidade das informações dos fatos descritos, através de suas vivências e emoções e do significado atribuído às mesmas.

No método história de vida, durante a entrevista, o sujeito reflete sobre sua vida, enquanto a narra no contexto do presente, liberando seu pensamento crítico, que, além de selecionar os fatos, determina o significado atribuído a eles, o que proporciona um verdadeiro balanço de sua vida (Ribeiro e Santos ${ }^{3: 49}$ ).

A aproximação com a enfermeira deu-se através de uma ex-colega sua, que, enobrecendo o seu trabalho na área de saúde pública, a indicou.

Após contato inicial por telefone, foi agendada uma visita em seu domicílio. Flora nos autorizou a gravação da entrevista e posterior doação ao acervo documental da Escola de Enfermagem Aurora de Afonso Costa. A entrevista foi realizada em maio de 1999 e teve a duração de duas horas.

Realizada a transcrição na íntegra de seu depoimento, fonte primária desta pesquisa, encontramos um fio condutor que caracterizava o grupo ao qual pertencia essa enfermeira, isto porque o indivíduo desenvolve muito de sua identidade pessoal, enquanto parte de um grupo de referência (Ribeiro e Santos ${ }^{3: 49}$ )

Para a análise dos dados, realizamos várias leituras do material transcrito, intercalando com a audição das fitas a fim de associar as características do discurso, tais como silêncios, contradições e hesitações. Dessa forma, destacamos no discurso, o tema saúde pública na trajetória profissional de Flora, pautadas nos objetivos da pesquisa.

Trabalhamos com uma única categoria de análise: a trajetória profissional em saúde pública de uma ex-aluna da Escola de Enfermagem do Estado do Rio de Janeiro.

\section{O INÍCIO DE UMA TRAJETÓRIA}

A personagem de nossa história é uma mulher nascida em 02 de agosto de 1921, no Maranhão. Ingressou na Escola de Enfermagem do Estado do Rio de Janeiro em 22 de junho de 1946, data de sua matrícula no Curso de Graduação em Enfermagem, e 
formou-se em 4 de abril de 1950. Dona de uma personalidade forte, determinada, entusiasta da saúde pública, escreveu vários poemas relacionados à atuação da Enfermagem no cenário da saúde, emociona-se quando fala da importância da enfermeira junto aos clientes e à comunidade, principalmente com as crianças, pois para ela a criança é o maior veículo de propaganda na construção e consolidação da cidadania dos indivíduos. Quando se orienta as crianças para agirem na comunidade elas se tornam portadoras, as mensageiras da saúde.

Flora ao concluir seus estudos, antes mesmo de sua formatura, foi para Recife como bolsista do Serviço Nacional de Tuberculose, a fim de organizar um hospital de tuberculose:

Como bolsista [...] estaria à disposição depois que se formasse para trabalhar em qualquer estado do Brasil onde houvesse necessidade. Então, ela mandou ... na última aula de problemas profissionais a Dona Aurora - minha grande diretora, uma pessoa inestimável um valor ... uma enfermeira de altíssimo padrão, ela perguntou para onde cada aluno gostaria de ir. E eu disse que queria ir para o Recife. E aí me mandaram para Recife antes mesmo da minha formatura e lá fomos quebrar pedra dentro do hospital, porque tivemos que travar uma batalha muito grande. Nunca tinha havido enfermeira e os médicos não aceitavam e, até porque, naquela época a enfermeira ganhava muito mais do que um médico, lá no Recife. $E$ isso, foi uma barreira muito grande que nós encontramos. Passei dois anos no Recife e de lá eu vim para a Saúde Pública do Resende ...

Por um aborrecimento que teve no hospital com um médico, largou o Ministério, pediu demissão e foi atuar na Saúde Pública, com uma remuneração menor.

Flora ficou pouco tempo no Centro de Saúde do Resende $^{c}$ e iniciou sua trajetória profissional em Niterói ${ }^{d}$ ao ser transferida para dirigir o Sanatório Azevedo Lima, hoje Hospital Azevedo Lima, onde permaneceu até 1956.

[...] não queria mais continuar no hospital e fui para a Saúde Pública, fui para o Centro de Saúde São Lourenço ${ }^{\text {e }}$... é hoje o Carlos Antonio da Silva, que o Carlos Antonio da Silva foi meu contemporâneo de faculdade ... era um médico assim, muito estimado pelos pacientes [...] Lá fazia serviço de saúde pública que foi uma continuação do que eu fazia quando aluna, que aluna em saúde pública ela visitava tudo ... começava pelo fichário. Primeiro organizamos o fichário, depois dividíamos a unidade sanitária, dividia toda a área em zonas, chamadas zonas sabe, um dois e três, e mandava, e você tirava as fichas daqueles pacientes e ia visitar, levava na sua maleta balança para pesar neném, remédios para pequenos curativos, tudo. $E$ você ali quando chegava no domicílio ensinava, inclusive, fazer comida do neném, dar o banho do neném, pesar o neném e fazer aquele acompanhamento e dar toda a orientação assim ... porque a Enfermagem é um horizonte de grande alcance, você dentro de uma residência você pode ensinar tudo. E depois trazia aqueles dados todos e fazia todas as observações, e se precisasse encaminhar alguém da família para a unidade sanitária você fazia um bilhetinho e mandava com 0 cliente e ele chegava na unidade tinha prioridade para ser atendido porque era encaminhado por nós.

Como bem ressalta Flora, as alunas eram preparadas para atuar junto à comunidade, o enfoque sanitário era marcante nessa época. 0 sistema de saúde brasileiro era do sanitarismo campanhista de combate às doenças de massa, com forte concentração de decisões e um estilo repressivo de intervenção sobre os corpos individual e social (Mendes ${ }^{4}$ ).

Trabalhar tanto no Sanatório Azevedo Lima como no Centro de Saúde São Lourenço era uma continuidade de sua vida acadêmica, pois a sede provisória da Escola de Enfermagem e do internato, funcionou até 1947, em dois pavimentos do Sanatório Azevedo Lima, por concessão do Serviço Nacional de Tuberculose. E o Centro de Saúde Modelo de São Lourenço era utilizado como campo de estágio das alunas (Fernandes ${ }^{5}$ ).

A partir da década de 50 , com o processo de industrialização acelerada do país, pondo fim ao modelo econômico agroexportador e um deslocamento da economia para os centros urbanos, a massa operária tinha que ser atendida pelo sistema de saúde, a fim de manter e restaurar a sua força reprodutiva (Mendes ${ }^{4}$ ). Relembrando esse momento diz Flora:

Havia uma coisa chamada fornecimento de carteira de saúde para toda a população trabalhadora. Tudo que era operário era obrigado a ter carteira de saúde. Nessa carteira de saúde, o cliente deveria ter vacina antivariólica, vacina antitetânica, raio $X$ todos esses exames e depois então era feita a carteira selada, documentada e o médico assinava. Se precisasse, se você percebia que o cliente tinha alguma coisa assim anormal, você encaminhava ou ao serviço de dermatologia ou para o serviço de sífilis, e aí ia muito a visão da enfermeira ... porque você quando fazia aquela triagem, na hora que fazia fila da clientela você ia observando, se você visse algum cliente com aspecto assim meio suspeito de hanseníase: "O Sr. quer vir comigo aqui no serviço de dermatologia? 0 Sr. está com essa mancha assim, vamos ver o que é!", porque não forneciam a carteira mesmo. Então íamos fazendo aquela triagem e encaminhando. 
No final de década de 50, Flora adquiriu uma casa próxima ao antigo Centro de Saúde Santa Rosa ${ }^{\dagger}$, que funcionava na rua Mário Vianna, no bairro de Santa Rosa, em Niterói. E assim solicitou sua transferência para esta unidade.

Lembrando saudosamente do Centro de Saúde Santa Rosa, recita o poema que escreveu naquela época para o velho casarão:

Aquele casarão de paredes velhas, de chão encardido, de pilastras ruídas, aquela casa que onde o dia-a-dia era todo cheio de tanta gente aflita, de crianças tristes, de bebês sorrindo, de mães sorridentes esperando os filhos, onde o velho, o moço, o que vai começar [...], o que vai terminar, o que vai enfrentar um vestibular; 0 que vai começar a erguer tapumes [...], levantar paredes; erguer edifícios; nesse casarão sujo, acabado, onde sempre esteve em cada parede, em cada recanto, toda a esperança de realizar, neste casarão já quase em ruínas, passaram gênios, os sábios, os tolos, os esperançados, os desiludidos, neste casarão - Escola da Vida, para você doutor, para você enfermeira, para você dentista, nesse casarão você atendente, você servente, chorou, sorriu, sofreu, você viveu, esperou, sonhou enfim, você aprendeu a respeitar alguém, a dor, o sofrimento, você aprendeu ser gente, aprendeu sorrir, confortar, ensinar para a vida. Enfim, você ali se realizou no sorriso das crianças, no choro dos bebês, na incompreensão da humanidade, você enfim venceu! (Flora)

A trajetória inicial de Flora evidencia o seu compromisso com a Enfermagem e a prática dos ensinamentos apreendidos durante a sua formação. Flora sempre ressalta a importância da diretora da Escola de Enfermagem, Dona Aurorag ${ }^{9}$, como modelo de enfermeira, uma enfermeira de altíssimo padrão. Graças a ela, as alunas aprenderam a atuar com determinação, conta Flora.

\section{FAZENDO E VIVENCIANDO A SAÚDE PÚBLICA EM NITERÓI}

Ao ser transferida, a pedido, para o Centro de Saúde Santa Rosa, Flora iniciou seu trabalho com a população carente solicitando que fosse encaminhada para a região de Pendotiba:

Eeu sempre pedi, sempre gostei de trabalhar com a população mais carente, com a área mais de periferia, [...] Quero! É mato?! Eu quero ir para o mato, eu sempre gostei. Ah, gente! Não me bote em área sofisticada não! Eu amarrava meu lenço na cabeça [...] por causa de poeira e era mais cômodo para mim [...] eu pegava e botava minha maleta e vestia meu uniforme azul, e eu ia de uniforme para a unidade [...] as auxiliares usavam guarda pó [...] e a primeira coisa que eu fiz foi o levantamento das escolas existentes na área.

Flora conta que, ao chegar, pela manhã, no Centro de Saúde, fazia educação sanitária com os clientes que estavam aguardando a consulta médica, pois sempre gostou muito de conversar. E depois ia para a região sob sua responsabilidade.

[...] Havia uma coisa assim muito curiosa, aquelas mães com aquele bando de filhos e eu dizia "Minha filha, mas você, como é que você pode cuidar dessas crianças todas! E como é que você vai alimentar essas crianças?" "Mas a Senhora sabe, o marido está com..." "Olha minha filha, quando você tiver com vontade de ir para a cama com o marido você vá para o quintal, capina o quintal, cava buraco, planta uma horta!" E elas morriam de rir ..., e nisso eu ia dando uma espécie de orientação para elas evitarem. Com um monte de filhos elas não tinham condições mesmo de ... e depois aí eu fazia meu trabalho, até oito horas, oito e meia elas estavam ali eu dava essas orientações. E, eu ia para a minha hora de trabalho, eu amarrava um lenço na cabeça e ia trabalhar.

A educação sanitária, nos moldes de sala de espera, era tão natural para a nossa enfermeira que ela não considera como sendo um trabalho. Para ela, o trabalho seria depois, quando estivesse em sua área sanitária.

Flora recorda que seu trabalho foi muito apoiado pelo então diretor do Centro de Saúde Santa Rosa - Dr. Cláudio Valadares, o qual valorizava muito as ações sanitárias na comunidade. E menciona sua fala: 0 sanitarista nasce, não se faz, porque saúde pública é uma coisa que vem de dentro de você para fora. Não adianta você querer incutir princípios de saúde pública quando você não tem a alma de sanitarista.

Em sua área sanitária de Pendotiba, trabalhando com mais três funcionários, iniciou suas atividades pelo levantamento das escolas existentes na localidade, porque:

[...] Eu acho que saúde pública não se faz com adulto. Impregnar saúde pública em adulto, é modificar hábitos e modificar hábitos em adultos é difícil. $E$ então, você tem que trabalhar o quê? A escola, o pré-escolar e o escolar, então se você concentrar suas atenções nesses dois grupos você terá toda uma população formada, sanitariamente formada

0 contato inicial de Flora era com a diretora da escola e as professoras, fazendo uma conscientização da necessidade de se trabalhar educação sanitária com as crianças. Formou 
- Pelotão de Saúde com as crianças que cursavam a terceira e quarta série do primário. Elas eram ensinadas na escola e preparadas para agirem na comunidade, eram os portadores da saúde na sua comunidade.

Com linguagem simples e acessível às crianças, os princípios básicos sobre vacinação eram explicados:

E vacina é o quê? Vacina é uma maneira que você tem de prevenir doença. E eu dizia assim: "Olha, nós temos um bocado de soldadinhos aqui dentro. Então, injeto isso em vocês e esses soldadinhos vão formar uma barreira dentro do seu organismo para combater com os outros agressores que são os germes da doença ..."

Com as devidas orientações, o Pelotão de Saúde agia na comunidade e repassava os ensinamentos apreendidos. Como conseqüência, a demanda de clientes à unidade de saúde aumentou consideravelmente. As crianças usavam uma cruz vermelha na blusa do uniforme colegial e consideravam uma grande distinção em seu meio, com direito, inclusive, a formatura.

Incentivadas, as crianças incorporavam o espírito sanitário e participavam da campanha de vacinação da comunidade, coordenada por Flora:

Agora nós vamos fazer a vacinação da comunidade! Olha (ri), armavam uma barraca, a nossa mesa de trabalho embaixo de uma árvore, dentro de um botequim, em qualquer lugar. Você chegava, armava e conversava e chamava, e pegava essas crianças e dizia assim 'Olha, vamos fazer hoje a campanha um por dois! E o que era a campanha um por dois? Você é vacinado - um. E aí, você tem que trazer dois. Aí, daqui a pouco nós dizíamos 'Olha, a campanha é um por três!' Olha eles se metiam naqueles matos, minha filha, aqueles garotinhos correndo, aquela turma desesperada e diziam: 'Olha Dona Flora, eu trouxe três!' E assim, nós íamos vacinando o pessoal.

0 trabalho de Flora teve grande repercussão na comunidade de Pendotiba e através das crianças, outros problemas eram reportados a ela. De posse dessas informações, Flora partia para a sua avaliação diagnóstica. Citando as falas de algumas crianças, relembra:

[...] A criança é uma coisa fabulosa, e eles diziam: 'Olha, lá naquele tal lugar assim perto de Maria Paula, Dona Flora, tem uma família que não dá leite para as crianças'. Pergunta assim: 'o que você prefere cachaça ou leite?' e 'quero cachaça' Aí eu fui verificar e era mesmo, menina, uma pobreza! ... Então, aí eu fazia um trabalho em cima daquele grupo e fomos diversificando ...
A diversificação do trabalho comunitário ensejou a participação, dentro da escola, do médico no atendimento às crianças matriculadas e extensivo às mães e seus irmãos. Outro ponto trabalhado por Flora foi a observação da alimentação precária das crianças do jardim de infância, o que resultou na proposta de inserção da merenda escolar, o que até então não era desenvolvido pelas autoridades públicas.

Lembrando das crianças do jardim de infância, relembra quando pediu para que fechassem os olhos e sonhassem, a fim de verificar a questão social das famílias. E nesse momento emociona-se:

Agora todo mundo vai contar para a tia o que sonhou!' Olha, eu fiquei tão arrasada porque 90\% das crianças sonhavam com pão, com café, com a banana ... (pausa, emoção). Nnguém pensava na carne, ninguém falava em carne, era pão, banana, um pedaço de doce, básico. Menina, eu cheguei na unidade 'Doutor Cláudio eu estou apavorada!' e '0 quê que foi?' Contei para ele e ele disse: 'Dona Flora!' E aí nós começamos a fazer aquele movimento para ver se conseguia alimentação, a merenda escolar. Olha minha filha, para você ver quanto a Enfermagem é capaz de fazer, de detectar os problemas e vai jogando para adiante, que aquilo é uma corrente. Você faz aqui e joga para cá e esse nível joga para o outro até conseguir o objetivo.

Mesmo com a falta de incentivos financeiros por parte das autoridades públicas para esse tipo de trabalho:

Era um trabalho que você fazia por amor, por consciência, pensando num Brasil melhor, num estado melhor, porque eu dizia sempre; 'Meu Deus!' ... A saúde pública era a única salvação para uma população carente. Porque, eu ensinava, nós ensinávamos, [...] 'Deixa eu fazer a comidinha da criança!', como eles deviam aproveitar as ervas que existiam. Eu saía com eles pelo mato mostrando 'Olha isso aqui você pode fazer uma sopa, tá, tá, tá!

Nos dias atuais, ouvimos muitas reclamações sobre o financiamento da saúde, e isso outrora também ocorria. Contudo, Flora tem uma explicação, segundo os valores adquiridos durante a sua formação:

Por causa da formação da enfermeira, primeira coisa é a conscientização da enfermeira, é trabalhar não pelo dinheiro, porque nós ganhávamos uma micharia. Você veja, hoje sou aposentada do estado e ganho 350 reais! Você vê quanto eu ganhava, quanto uma enfermeira ganhava naquela época. Mas, a gente tinha 
amor, trabalhava por amor, por ideal, por querer fazer, por querer beneficiar a população, [...] Nós não visávamos o dinheiro, porque no momento que mercantiliza o profissional ele perde muito, porque não é o dinheiro que te faz. Não é o dinheiro que te dá consciência do seu dever. É tua responsabilidade.

\section{O FLORESCER DAS SEMENTES}

0 fortalecimento da cidadania dos clientes foi também trabalhado por Flora. Quando os clientes procuravam a unidade de saúde, já estavam cientes de seus direitos, sabiam o que queriam:

Quando eles vinham para o posto de saúde, eles já vinham orientados para pedir alguma coisa 'Olha, eu quero que faça isso, assim, assim, comigo!' 'Ah, mas não ...' 'Não! Mas, a enfermeira disse que aqui tem isso assim, assim, para se fazer!'. Já vinham preparados, já requisitavam uma coisa que era direito deles, porque eu dizia assim 'Olha, vocês têm direito a ter saúde, vocês têm meios de ter saúde, vocês estão sendo orientados para ter saúde, e se vocês quiserem maiores subsídios vocês têm que ir ao posto de saúde tal assim, assim, que lá vocês vão encontrar o médico para lhe orientar, o médico para Ihe tratar!' E eles vinham, já vinham cientes e aí, às vezes, criavam um ... tinham que encontrar um médico, porque se não encontrassem eles iam ... 'Olha, a senhora me disse...'. Cobravam, isso é cidadania, a cobrança que ele faz em cima de você.

Durante trabalho desenvolvido para aplicação de BCG em crianças, Flora identificou que, enquanto as crianças moradoras na periferia apresentavam reação negativa ao teste de PPD, as crianças da área de Icaraí, considerada como área nobre, apresentavam reação positiva. Frente a este fato iniciou uma pesquisa de rastreamento entre os familiares, a fim de descobrir a fonte da possível infecção, tendo como resultado respostas negativas. É quando Flora incluiu também outros comunicantes, no caso, as babás, as quais apresentaram reação positiva ao teste de PPD:

Começamos a fazer um trabalho com as babás e conscientizando as famílias para exigir a carteira de saúde das babás. Foram as primeiras carteiras de saúde de domésticas. E foi exatamente por causa disso. Então, elas eram encaminhadas para o centro de saúde, faziam exames de fezes, faziam o teste de PPD, faziam Raios-X, tomavam as vacinas e aí era fornecida a carteira de saúde para elas.

Esse fato merece uma atenção especial, pois até então, nessa época, a exigência para a emissão da carteira de saúde abrangia apenas a classe operária.

Por volta de 1978, recorda Flora, começaram a ser preparados os primeiros agentes de saúde de Niterói, em Pendotiba. A primeira turma era composta por seis a oito mulheres, as quais foram do antigo Pelotão de Saúde formado por Flora.

Esses fatos vêm demonstrar o reflexo do trabalho de Flora com as crianças na saúde pública do município de Niterói, bem como com toda a comunidade.

\section{CONSIDERAÇÕES FINAIS}

A história da trajetória profissional de Flora no campo da saúde pública nos aponta a importância da atuação da enfermeira junto à comunidade, bem como a relevância do enfoque de saúde pública em sua formação na Escola de Enfermagem do Estado do Rio de Janeiro. 0 trabalho realizado por essa enfermeira, segundo ela, foi uma continuação de sua vida acadêmica.

As contribuições da Escola com ênfase na área da saúde pública consolidaram-se através do preparo das enfermeiras para lidarem com as mais variadas adversidades no campo da saúde, como nos conta Flora.

Interessante que, ao revermos a trajetória de uma enfermeira em saúde pública, àquela época, observamos o quanto as ações desenvolvidas se assemelham ao trabalho que hoje é proposto para os agentes comunitários de saúde, supervisionados por enfermeiros.

Portanto, ao propormos resgatar uma prática de enfermagem de tamanha magnitude, buscamos mostrar às novas gerações o quão importante é (re)construirmos a nossa História, pois um povo que se esquece do seu passado tende a repetir os seus erros, e passa a ter maiores dificuldades em alcançar o sucesso.

Bem, essa é a nossa versão da história! 


\section{Referências}

1. Nogueira LT. 0 ensino de história da enfermagem e o resgate da memória: panorama nos cursos de enfermagem da região nordeste. Esc Anna Nery Rev Enferm 2000 dez; 4(3): 321-32.

2. Santos TP, Escudeiro CL, Abreu ASGT, Chagas Filho GAS (Re)construindo a história da Escola de Enfermagem Aurora de Afonso Costa. Anais da $8^{a}$ Semana Científica da Escola de Enfermagem Aurora de Afonso Costa[CD-ROM] ; 2000 out 6-10; Niterói (RJ), Brasil, Niterói(RJ): EEAAC; 2000.

3. Ribeiro MGM, Santos RS. 0 método "história de vida" e seu uso em pesquisa de enfermagem com gestante HIV positivo. Esc Anna Nery Rev Enferm 2000 abr; 4(1): 47-54.

4. Mendes EV. A política de saúde no Brasil nos anos 80: a conformação da reforma sanitária e a construção da hegemonia do projeto neoliberal. In: Mendes EV, organizador. Distrito Sanitário: o processo de mudança das práticas sanitárias do Sistema Único de Saúde. $3^{\mathrm{a} e d}$ São Paulo (SP): HUCITEC; 1995.

5. Fernandes CAF. História da Escola de Enfermagem do Estado do Rio de Janeiro. Niterói (RJ): UFERJ; 1964.

\section{Sobre as Autoras}

Zenith Rosa Silvino

Professora Adjunta do Departamento de Fundamentos e Administração em Enfermagem da EEAAC/UFF. Doutora em Enfermagem pela EEAN/ UFRJ. Diretora de Enfermagem do Hospital Universitário Antônio Pedro/UFF. Coordenadora do Núcleo de Estudos em Cidadania e Gerência na Enfermagem (NECIGEN).

\section{Fátima Helena do Espírito Santo}

Professora Adjunta do Departamento de Enfermagem Médico-Cirúrgica da EEAAC/UFF. Doutora em Enfermagem pela EEAN/UFRJ. Membro do NECIGEN.

\section{Cristina Lavoyer Escudeiro}

Professora Adjunta do Departamento de Enfermagem Médico-Cirúrgica da EEAAC/UFF. Doutora em Enfermagem pela EEAN/UFRJ. Membro do NECIGEN.

\section{Notas}

a A Escola de Enfermagem Aurora de Afonso Costa recebeu este nome em homenagem à sua fundadora e primeira diretora, através da Resolução 34/99 do Conselho Universitário da Universidade Federal Fluminense, em 31 de março de 1999.

${ }^{\mathrm{b}}$ A Escola de Enfermagem do Estado do Rio de Janeiro, criada em 18.10.1944, foi incorporada à Universidade do Estado do Rio de laneiro, atual Universidade Federal Fluminense, através da Lei $n^{0}$ 808, de 11/03/1950. Ressaltamos que Niterói, na época, era a capital do Estado do Rio de Janeiro.

c Localizado na capital do Distrito Federal, depois Estado da Guanabara, hoje cidade do Rio de Janeiro, capital do atual Estado do Rio de Janeiro.

d Capital do antigo Estado Rio de Janeiro, hoje a segunda maior cidade do atual Estado do Rio de Janeiro.

e Primeiro Centro de Saúde a ser criado no município de Niterói, era o Centro de Saúde da Capital.

† O Centro de Saúde Santa Rosa foi inaugurado em 31.01.1953 (no chamado "velho casarão"). A partir de dezembro de 1997, recebeu a denominação de Policlínica Comunitária Santa Rosa e está instalado em sede própria, na Rua Ary Parreiras, no bairro do Vital Brasil, Niterói, desde 12.11.1974.

9 Aurora de Afonso Costa foi a primeira diretora da Escola de Enfermagem do Estado do Rio de Janeiro, permanecendo neste cargo de 1944 a 1966 